www.jmscr.igmpublication.org

Impact Factor (SJIF): 6.379

Index Copernicus Value: 79.54

ISSN (e)-2347-176x ISSN (p) 2455-0450

crossrefDOI: https://dx.doi.org/10.18535/jmscr/v6i9.88

Journal Of Medical Science And Clinical Research

IGM Publication

An Official Publication of IGM Publication

\title{
An observational study on maternal and foetal outcome in twin Pregnancy
}

\section{Authors \\ Dr Richa Choudhary ${ }^{1 *}$, Dr Girija Kumari}

${ }^{1}$ Senior Resident, Department of Obstetrics and Gynaecology, Anugrah Narayan Magadh Medical College, Gaya, Bihar, India

${ }^{2}$ Associate Professor, Department of Obstetrics and Gynaecology, Anugrah Narayan Magadh Medical College, Gaya, Bihar, India

*Corresponding Author

Dr Richa Choudhary

Senior Resident, Department of Obstetrics and Gynaecology, Anugrah Narayan Magadh Medical College, Gaya, Bihar, India

Contact No: +91 7260031252, Email id: drrichachoudhary123@gmail.com

\begin{abstract}
:
Objectives: Objectives of our study was to evaluate the maternal and foetal outcome in mothers of twin pregnancy.

Methodology: A detail history, complete assessment such as gestational age, parity, nature of conception, use of ovulation induced drugs, maternal or obstetrics complications, foetal weight, foetal discordancy, foetal viability, malformations, abnormal vascular communications, presentations of foetuses were performed to all cases. Relevant investigations were performed. A continuous follow up of all cases were performed from throughout pregnancy to up to delivery and discharge.

Observations: Data was analyzed by using simple statistical methods with the help of MS-Office software.

Conclusions: Fertility age was commonly seen in mothers with age 20-30 years. Pre term labour was mostly seen in cases of twin pregnancy. Majorities of babies were foetal birth weight 1500-2000 grams. Second babies were more prone to malpresentation than first baby. Anaemia was the most common malpresentation. 20.5\% Neonatal morbidity and 5.5\% neonatal mortality rate were seen in cases of twin pregnancy.

Keywords: maternal outcome, foetal outcome, twin pregnancy.
\end{abstract}

\section{Introduction}

Twin pregnancy is considered as a high risk pregnancy. In USA it has been reported constant as $32 / 1000$ births (Chauhan et al., $)^{[1]}$ the lowest incidence 4/1000, whereas African countries have higher incidence of twins, up to $54 / 1000$ births reported from Nigeria (Fisk, 2007). ${ }^{[2]}$ There has been an increase in incidence of twins due to multiple reasons such as a rise in the number of women conceiving at an advanced age and in increase in use of assisted reproductive techniques (Cruikshank, 2007). ${ }^{[3]}$ Pregnancy is associated with a high risk of maternal and neonatal complications such as preterm labour, pregnancy 
induced hypertension, antepartum and postpartum haemorrhage, fetal malformations, and perinatal death. Prematurity which is the commonest antenatal complication accounts for the majority of perinatal death. ${ }^{[4]}$

Multiple pregnancies in developing countries expose mother and infants to extremely high risks. As multiple births can contribute significantly to maternal and perinatal morbidity and mortality, it is important to investigate the magnitude of the increase in feto-maternal risk. The outcome of twin pregnancies across developing countries has not been extensively investigated. Twin birth registries are rare in low- and middle-income countries (LMICs) ${ }^{[5]}$ and twin-specific research is generally on hospital-based cohort studies, secondary analyses of interventional trials or retrospective analyses of Demographic and Health Survey (DHS) data, all with significant limitations and bias ${ }^{[6,7]}$. Objectives of our study were to evaluate the maternal and foetal outcome such as maternal age, gestational age, parity, malpresentaion, foetal birth weight and neonatal morbidity and mortality of cases in twin pregnancy.

\section{Materials and Methods}

This present study was conducted in department of Obstetrics and Gynaecology, Anugrah Narayan Magadh Medical College, Gaya, Bihar India during a period from January 2017 to December 2017.

A total 100 cases of pregnant women with twin gestation were enrolled in this study.

Attendants/entire subjects signed an informed consent approved by Institutional ethical committee of Anugrah Narayan Magadh Medical College, Gaya, Bihar was sought.

\section{Methods}

A complete assessment such as gestational age, parity, nature of conception, use of ovulation induced drugs, maternal or obstetrics complications, foetal weight, foetal discordancy, foetal viability, malformations, abnormal vascular communications, presentations of foetuses and relevant investigations were performed to all cases. A continuous follow up of all cases were performed from throughout pregnancy to up to delivery. Mother and babies were followed up till discharge.

All premature babies were given nasogastric foods or through parenteral fluids and were kept under supervision in ICU, till capable of taking breast feeds.

\section{Statistical Analysis}

Data was analyzed by using simple statistical methods with the help of MS-Office software.

\section{Observations}

A total of 100 cases of twin pregnancy with age group 20 years to greater than 30 years were enrolled in this study. Majority of cases $84(84 \%)$ were in age group of 20-30 years.

Table 1 Age of pregnant women

\begin{tabular}{|l|c|c|}
\hline Age & No. of cases & percentage \\
\hline$<20$ years & 13 & $13 \%$ \\
\hline $20-30$ Years & 84 & $84 \%$ \\
\hline >30 years & 3 & $3 \%$ \\
\hline Total & 100 & $100 \%$ \\
\hline
\end{tabular}

Table 2 Parity of cases with twin pregnancy

\begin{tabular}{|l|c|c|}
\hline Parity & No. of cases & Percentage \\
\hline Primi & 55 & $55 \%$ \\
\hline Multi & 45 & $45 \%$ \\
\hline
\end{tabular}

Parity of cases was 55(55\%) primi gravida and 45 $(45 \%)$ multi gravida.

Table 3. Gestational age

\begin{tabular}{|l|c|c|}
\hline Gestational age & No. of cases & Percentage \\
\hline$<34$ weeks & 32 & 32 \\
\hline $34-37$ weeks & 55 & 55 \\
\hline >37 weeks & 13 & 13 \\
\hline
\end{tabular}

In this present study, majority of cases 55(55\%) were gestational age 34-37 weeks. 32(32\%) cases were gestational age <34 weeks, and 13(13\%) cases were $>37$ weeks.

Table 4 Antenatal complications

\begin{tabular}{|l|c|c|}
\hline Antenatal complication & No. of patients & Percentage \\
\hline Preterm labour & 87 & $87 \%$ \\
\hline PIH & 13 & $13 \%$ \\
\hline
\end{tabular}


In this study, preterm labour were seen in $87(87 \%)$ cases and (PIH) pregnancy induced hypertension was seen in $13(13 \%)$ cases.

Table 5 Relation between perinatal outcome and mode of delivery.

\begin{tabular}{|l|c|c|}
\hline Mode of delivery & No. of patients & Percentage \\
\hline Spontaneous & 67 & $67 \%$ \\
\hline Caesarean & 27 & $27 \%$ \\
\hline Instrumental vaginal & 6 & $6 \%$ \\
\hline
\end{tabular}

Majority of cases $67(67 \%)$ were spontaneous mode of delivery. 27(27\%) were delivered by caesarean. Instrumental vaginal delivery was $6(6 \%)$.

Table 6 Foetal birth weight

\begin{tabular}{|l|c|c|}
\hline Foetal birth weight & No. of patients & Percentage \\
\hline$<1500$ grams & 64 & $32 \%$ \\
\hline 1500 -2000 grams & 78 & $39 \%$ \\
\hline$>2000$ grams & 58 & $29 \%$ \\
\hline
\end{tabular}

$78(39 \%)$ foetus were birth weight 1500-2000 grams. 64(32\%) foetus were birth weight $<1500$ grams. And 59(29\%) were foetus birth weight > 2000 grams.

Table 7 Malpresentation

\begin{tabular}{|l|c|c|}
\hline Malpresentation & No. of patients & Percentage \\
\hline First baby & 5 & $5 \%$ \\
\hline Second baby & 27 & $27 \%$ \\
\hline Anaemia & 34 & $34 \%$ \\
\hline Hydraminos & 12 & $12 \%$ \\
\hline APH & 9 & $9 \%$ \\
\hline PROM & 13 & $13 \%$ \\
\hline
\end{tabular}

In this present study, anaemia 34(34\%) was the most common malpresentation. And other malpresentations were PROM 13(13\%), hydraminos $12(12 \%)$ and APH 9(9\%). Second baby was the major risk for malpresentation.

Table 8 Sex of baby

\begin{tabular}{|l|c|c|}
\hline Sex of baby & No. of cases & Percentage \\
\hline Males & 126 & $63 \%$ \\
\hline Females & 74 & $37 \%$ \\
\hline
\end{tabular}

Majorities of babies were males 126(63\%).

Female babies were 74(37\%).

Table 9 Perinatal outcome

\begin{tabular}{|l|c|c|}
\hline Perinatal outcome & No. of cases & Percentage \\
\hline Live birth & 185 & $92.5 \%$ \\
\hline Still birth & 15 & $7.5 \%$ \\
\hline
\end{tabular}

Out of total 200 babies, number of live birth was $185(92.5 \%)$ and $15(7.5 \%)$ still birth was $15(7.5 \%)$.

Table 10 Neonatal outcome

\begin{tabular}{|l|c|c|}
\hline Neonatal outcome & No. Of cases & Percentage \\
\hline ICU admission & 108 & $54 \%$ \\
\hline Neonatal morbidity & 41 & $20.5 \%$ \\
\hline Neonatal mortality & 11 & $5.5 \%$ \\
\hline
\end{tabular}

Out of 200 babies, 108(54\%) babies were admitted in intensive care unit. Neonatal morbidity was seen in $41(20.5 \%)$. And neonatal mortality was seen in11 (5.5\%).

Table 11 Causes of neonatal death.

\begin{tabular}{|l|c|c|}
\hline Cause of neonatal death & No. of cases & Percentage \\
\hline RDS & 13 & $6.5 \%$ \\
\hline Septicaemia & 17 & $8.5 \%$ \\
\hline Pulmonary haemorrhage & 7 & $3.5 \%$ \\
\hline DIC & 3 & $1.5 \%$ \\
\hline
\end{tabular}

Major causes of neonatal death was septicaemia 17 (8.5\%), RDS 13(6.5\%), pulmonary haemorrhage $7(3.5 \%)$ and DIC 3(1.5\%).

\section{Discussion}

Traditionally multiple pregnancies are regarded to be unfavourable, probably due to the poor perinatal outcome, increased maternal mortality and morbidity, long term developmental issues and the expensive treatment involved.

Twin pregnancy is considered as one of high risk for both mother and baby.

Here, in our present study we were studied on maternal and foetal outcome of 100 cases of twin pregnancy. Majority of cases $84(84 \%)$ were in age group of 20-30 years. Least number of cases $3(3 \%)$ were in age greater than 30 years.

Similar study was conducted by Abdelmoneim, E, et al. (2016). ${ }^{[4]}$ In their study most of mothers were falling between the age group 23-32 years of age. Similar results was also found by Spellacy et al., 1990; Yuel and Kaur, 2007. ${ }^{[8,9]}$

Since the early 1970s, several overview studies have been published in which figures from a large number of smaller studies were brought together. The overall conclusion drawn from these figures was that natural twinning rates were low in East 
Asia and Oceania (less than 8 twin births per 1000 births), intermediate in Europe, USA and India (9-16 per 1000 births) and high in some African countries (17 and more per 1000 births). ${ }^{[10,11]}$

In this present study, cases of primi gravida were $55(55 \%)$ and multi gravida $45(45 \%)$.

Amiben V. Gajera, et al. (2015) also supported the findings of our study, they were stated that with regards to parity higher incidence was seen in primi gravida and least was in multi gravida. ${ }^{[12]}$

In this present study, majority of cases $55(55 \%)$ were gestational age 34-37 weeks. 32(32\%) cases were gestational age < 34 weeks, and 13(13\%) cases were $>37$ weeks. We were seen that most common gestational age was 34-37 weeks.

Hada A, et al. (2016) were found that most common gestation age at delivery was 29-36 weeks in $47.1 \%$ cases. ${ }^{[13]}$ In study of Sheela et al (2014) most common gestational age at the time of delivery was $32-36$ weeks in $67 \%$ cases. $^{[14]}$

In this study, preterm labour were seen in $87(87 \%)$ cases and pregnancy induce hypertension $(\mathrm{PIH})$ were seen in $13(13 \%)$ cases.

The incidence of hypertensive disorders of pregnancy was significantly higher in twin pregnancies ${ }^{[15,16]}$. This has been attributed to exposure to superabundant chorionic villi in twin pregnancies $^{[17]}$.

In this present study, most of the cases $67(67 \%)$ were undergone spontaneous mode of delivery. $27(27 \%)$ were delivered by caesarean section and $6(6 \%)$ through Instrumental vaginal delivery.

Prematurity is the leading cause of neonatal death among twin gestations. The higher rate of preterm delivery compromises the survival chances of the neonates and increases their risk of lifelong disability.

Mahita Reddy A, et al. (2016) were studied on twin pregnancy and found that Vaginal delivery occurred in 165 cases, in that spontaneous being 149, forceps being 3 and induced 14. Caesarean delivery occurred in 135 cases with elective LSCS being 42 and emergency LSCS being 92. ${ }^{[18]}$

In this present study, most common malpresntation was anaemia $34(34 \%)$. Others were premature rupture of membrain (PROM) $13(13 \%)$, hydrominos $12(12 \%)$ and anteparttum haemorrhage $9(9 \%)$. Malpresentation was greatly seen in second baby $27(27 \%)$.

Anaemia. It may be due to increased fetal drain on maternal iron and folate stores and increased hemodilution that accompanies twin gestation. Women with twin pregnancies should be supplemented with prophylactic iron (200 $\mathrm{mg}$ /day) and folic acid (1 mg/day).

PROM: Excessive growth of uterus in twin gestation results in early opening of the cervix \& exposure of the fetal membranes to the bacterial flora of the vagina leading to amnionitis with intact membranes and in severe cases to amnionitis with ruptured membranes. Hence infections of the urinary tract, the cervix and the vagina in these mothers, must be treated aggressively.

Acute hydramnios is more common in monozygotic twin pregnancies. Chronic hydramnios incidence is same in both dizygotic and monozygotic twin pregnancies. In our study there was no maternal mortality.

In this present study, majorities of foetus $78(39 \%)$ birth weight was 1500-2000 grams. 64(32\%) foetus were birth weight $<1500$ grams. And $59(29 \%)$ were foetus birth weight $>2000$ grams. Number of male babies was $126(63 \%)$ and female babies were 74(37\%).

Amiben V. Gajera, et al (2015) ${ }^{[12]}$ were found that the incidence of having a baby with low birth weight (of less than 2500 gms) was 86.9\%; however, Bangal et al showed an incidence of $82 \%$.

In this present study, out of total 200 babies, number of live birth was $185(92.5 \%)$ and still birth was $15(7.5 \%)$. 108(54\%) babies were admitted in intensive care unit. Neonatal morbidity was $41(20.5 \%)$. And neonatal mortality was $11(5.5 \%)$. Major causes of neonatal death was septicaemia $17(8.5 \%)$, RDS $13(6.5 \%)$, pulmonary haemorrhage 7(3.5\%) and DIC 3(1.5\%).

Similar study was conducted by Vidyadhar B. Bangal, et al (2012). They were studied on 100 
cases of twin pregnancy and found that there were 15 stillbirths and 20 early neonatal deaths. Overall perinatal deaths were $17.5 \%$.Prematurity and low birth weight predisposed majority of early neonatal deaths. These small babies suffered from respiratory distress 9 cases $(4.5 \%)$, pulmonary hemorrhage (4cases), septicemia 12cases (6\%) and disseminated intravascular coagulation 9cases $(4.5 \%){ }^{[19]}$

Dr. Deepthi H. R, et al $(2015)^{[20]}$ stated that perinatal morbidity requiring NICU admission was $36.6 \%$ mainly due to preterm deliveries and low birth weight. Similarly seen in Chowdhury et al $^{[21]}$ and by Papierniek et al. ${ }^{[22]}$

\section{Conclusion}

This present study was concluded that the major fertility age was 20-30 years of mothers of twin pregnancy. Spontaneous mode of delivery was commonly seen. Majorities of cases were pre term labour. Majorities of babies were foetal birth weight 1500-2000 grams. Second babies were prone to malpresentation than first baby. Anaemia was the most common malpresentation. Major causes of neonatal mortality were septicaemia and respiratory distress syndrome. Neonatal morbidity rate was $20.5 \%$ and neonatal mortality rate was $5.5 \%$ in cases of twin pregnancy. Hence we concluded that pre term labour, anaemia, septicemia and respiratory distress syndrome were common causes of neonatal morbidity and mortality of cases of twin pregnancy.

\section{References}

1. Chauhan, S. P., Scardo, J. A., Hayes, E., Abuhamad, A. Z., Berghella, V. 2010.Twins: prevalence, problems, and preterm births. Am J Obstet. Gynecol., 203:305-15.

2. Fisk, N. M. Multiple pregnancy, 2007 In: Edmond D.K, editor. Dewhurst's textbook of Obstetrics \& Gynaecology. 7th ed. Massacheusetts: Blackwell Publishing; pp 166-76.
3. Cruikshank, D. P. 2007. Intrapartum management of twin gestations. Obstet. Gynecol., 109:1167-76.

4. Abdelmoneim, E. M. Kheir, Reem, B.A. Ali and Samah, M. H. Abdelmonim, 2016. "Maternal and foetal outcome of twin pregnancy in a tertiary maternity hospital in sudan. International Journal of Current Research, 8, (04), 30728-307731.

5. Sumathipala A, Siribaddana S, De Silva N, Fernando D, Abeysingha N, et al. (2002) Sri Lankan twin registry. Twin Res 5: 424-426.

6. Aisien A, Olarewaju R. Twins in Jos Nigeria: a seven-year retrospective study. Med Sci Monit. 2000; 6: 945-50.

7. Uthman O, Uthman M. A populationbased study of effect of multiple birth on infant mortality in Nigeria. BMC Pregnancy Childbirth. 2008; 8: 41.

8. Spellacy, W. N., Handler, A., Ferre, C. D. 1990, A case control study of 1253 twin pregnancies from1982-1987, Perinatal data base 1990, Obstet Gynecol.;75(2):168-71.

9. Yuel, V. I., Kaur, V. 2007. An Analytical study of pregnancy outcome in multifetal gestation. J ObstetGynaecol India, 57(6): 509-512.

10. Bulmer MG, The Biology of Twinning in Man. Oxford: Oxford University Press 1970.

11. Nylander PPS The phenomenon of twinning. In: Barron SL, Thompson AM, editors. Obstetrical Epidemiology. London Academic Press 1983. pp. 143-165.

12. Amiben V. Gajera, Hiremath $P$. Basavannayya, C. Kavitha, Reshma Hiremath. Feto-maternal outcome in twin pregnancy. Int J Reprod Contracept Obstet Gynecol. 2015 Dec;4(6):1836-1839.

13. Hada A, Baghela AS, Sethi D. Study of maternal and foetal outcome in multiple pregnancy. J. Evolution Med. Dent. Sci. 2016;5(59):4069-4073, DOI: 10.14260/jemds/2016/932. 
14. Sheela SR, Patila A. A study of maternal and foetal outcome in multifoetal gestation at a rural based teaching hospital-a retrospective analysis. Int J Biol Med Res 2014;5(2):3994-7.

15. Bassey EA, Abasiattai AM, Udoma EJ, Asuquo EE. Outcome of twin pregnancies in Calabar, Nigeria. G J Med Sci., 2004; 3(1-2): 13-15.

16. Nwobodo EI. Bobzon DN, Obe J. Twin births at the University of Teaching Hospital: Incidence, pregnancy complications and outcome. Niger J Med., 2002; 11: 67-9.

17. Onwuzuruike BK, Onah HE. Caesarean section in twin pregnancies in Enugu, Nigeria. Journal of College of Medicine, 2004; 9(1): 8-11.

18. Mahita Reddy A., Madhavi KSS., Niharica. A study on risk of twin pregnancy. IAIM, 2016; 3(10): 139-145.

19. Vidyadhar B. Bangal, Shruti M Patel, Devendra N Khairnar. Study of maternal and fetal outcome in twin gestation at tertiary care teaching hospital. International Journal of Biomedical and Advance Research. 2012; $03: 10$.

20. Dr. Deepthi H. R, Dr. Pradeep M. R, Dr. Lalitha shivanna. Retrospective Study of Maternal and Perinatal Outcome of Twin Pregnancy in a Teaching Hospital. IOSR Journal of Dental and Medical Sciences (IOSR-JDMS). Jan 2015 ;14: 1 :29-32.

21. Chowdhury S. Clinical study on twin pregnancy Feps, Bangladesh college of physician and surgeons, Dhaka 1998.

22. Papiernik E, Keith L , Oleszczukff , Cervants A, what intervensations are useful in reducing the rate of pre term delivery in twins ?In; clinical obs and gynec 1998; P 13-22. 